\title{
THE UNIVERSITY OF ALBERTA CHEMICAL ENGINEERING CAPSTONE DESIGN COURSE GOES FLIPPED!
}

\author{
Marnie V. Jamieson ${ }^{1,3}$, Len Church ${ }^{1}$, Frank Vagi ${ }^{1}$, William Pick ${ }^{1}$, Tracy Onuczko ${ }^{2,3}$, John Nychka ${ }^{1}$, \\ Norma Nocente ${ }^{2,3}$, and John M. Shaw ${ }^{1}$ \\ University of Alberta Faculties of Engineering ${ }^{1}$ and Education ${ }^{2}$, Center for Teaching and Learning ${ }^{3}$ \\ mvjamies@ualberta.ca, jmshaw@ualberta.ca
}

\begin{abstract}
The Capstone Design Course instructional team was selected to participate in the digital learning initiative at the University of Alberta. The goals of this initiative are to increase student engagement and promote flexible, independent learning. The objectives of the instructional team were to enhance the interactions between instructors and student design teams in the face of increasing enrolment and to align the course strategically with attributes expected for graduating engineers set out by the University and elaborated in the Canadian Engineering Accreditation Board (CEAB) Guidelines. Existing course materials were redeveloped to an asynchronous online format for individual student engagement and related activities were completed in class. Course delivery effectiveness is being evaluated by comparison with previous cohorts, improvements in post course student self-assessment, student engagement and satisfaction, and will include post course interview and survey data. This preliminary report focuses on elements of course design and preliminary findings.
\end{abstract}

Keywords: CEAB Assessment, Digital Learning, Capstone Design, Course Design, Course Evaluation, Student Assessment, Student Engagement, Flipped Classroom, Problem Based Learning.

\section{INTRODUCTION}

\subsection{Motivation}

The goals of the University of Alberta digital learning initiative (to promote flexible, independent learning and increase student engagement) were combined with the capstone design course instructional objectives (to enhance quality interactions between design instructors and student design teams). The Capstone Design Course in Chemical Engineering is a project course where approximately 25 teams of 5-6 students each complete a unique industry sponsored design project. Students must research the project, identify and compare competing options using sustainable design criteria, develop a team structure, a project plan and schedule and then complete the design project. The five capstone design instructors teach as a team in the same section.

\subsection{Literature Review}

The field of engineering requires ongoing development of new professionals and scholars through effective education programs. Students who wish to work as engineers acquire knowledge of fundamental concepts, gain skills required to apply knowledge to tasks, solve problems, construct and validate models, and evaluate data produced, whether in research, design or operations contexts $[10,15]$. How best to prepare students and assist them to develop these skills is a complex issue involving consideration of curriculum, policy, accreditation, pedagogy, and institutional leadership [5, 9, 19]. The traditional lecture format, where instructors transfer their knowledge to largely passive students and which some suggest has not changed significantly in the last thousand years [4], continues to be the most widely used instructional approach in engineering education [10, 19], even though a growing body of education research indicates it is a less effective than active instructional approaches $[10,14,15,19]$. A recent review of discipline based education research (DBER) related to science and engineering found that:

... research-based instructional strategies are more effective than traditional lecture in improving conceptual knowledge and attitudes about learning. Effective instruction involves a range of approaches, including making lectures more interactive, having students work in groups, and incorporating authentic problems and activities $[5,15]$.

Why then, given the evidence that active learning methods are more effective, is the lecture format so common? A number of factors may serve as barriers to the implementation of active learning approaches $[2,10]$, 
one being "the persistent myth that all active learning methods require more faculty time than lecturing" [19]. While active learning approaches may require additional development time initially, effectively designed courses can ensure coverage of content as well as opportunities for active learning without significantly more faculty time [8]. This is the primary benefit of the flipped classroom.

\subsection{Problem Definition}

Previously, in the Chemical Engineering Capstone design course, lecture-format tutorials were provided in two-hour blocks twice weekly to support student learning and successful project completion. Thirty-minute team meetings with individual instructors, and open format question and work periods followed. The planned increase in enrolment from 125 students this year to 170 students next year requires more teams and this restricts the time for individual questions and meetings with instructors unless the instruction time is reduced.

\subsection{Solutions Considered}

A new course structure was developed using flipped classroom ideas and principles alongside technology advances in course delivery. Pre-class materials now typically comprise a brief video, a short reading, and a formative assignment to prepare students for in class interactive activities that apply online materials. Students submit brief reports based on in class activities at the end of class. Post-class students apply their learning to their open-ended design projects. Infeasible alternate solutions required additional in class time or additional instructors.

\subsection{Flipped Classrooms and Engineering}

Flipped classrooms, also called blended or inverted learning environments, change the way instructors and students work together. A key aspect of the flipped approach is the integration of face-to-face and online (individual) learning with the aim of enhancing the classroom experience with active learning [20]. For many instructors, a flipped approach means providing students with access to videos, readings, or other instructional material that enable students to learn concepts asynchronously prior to coming to class. Class time then becomes available for active learning which may include projects, collaborative work, problem based learning, or other activities [8, 10]. As such, a key feature of flipped learning is a shift from teacher-centered lectures to student-centered instruction [20]. Flipped approaches may also influence student engagement $[6,7,19]$.

Flipped classroom approaches have the potential to enhance the quality of engineering education by providing opportunities for instructors to implement active learning strategies during class time. Currently, there is a limited body of research that has investigated flipped approaches within the context of engineering courses; however there is evidence for the benefits of active learning approaches in engineering education [14, 17]. Where flipped or blended classes have been implemented in undergraduate engineering programs, there is evidence that student satisfaction is greater and that levels of class attendance, motivation, and collaboration among students is higher than in traditional lecture format courses [12]. Student engagement is widely acknowledged as being important to their post-secondary success [1] and development of conceptual understanding [11]. In addition, the connection between student engagement and active learning is well supported in the literature $[10,15]$. The impact of the implementation of a flipped classroom approach and active learning strategies on student engagement is a principal thread in the current study. Csikszentmihalyi's concept of flow $[3,16]$, wherein an individual is engaged when: they are intensely focused on their current activity, feel intrinsically rewarded and in-control, feel that the task is neither too difficult nor too easy, and may lose track of time (experience temporal distortion), underlies our work. His concept is illustrated in Figure 1.

\section{STUDENT ENGAGEMENT}

\subsection{Challenge vs Skill: Moving to the Flow Zone}

The Chemical Engineering design course is based on independent learning in an interactive team environment. Students collaborate to develop a team structure, a project scope and plan. A process was developed to guide students through individual preparation, contribution of work and ideas, team evaluation and integration of contributions, product production, tracking and reflection. In our experience, providing scaffolding and feedback for the learning experience is a critical part of the success of a project based course that relies on individual and team contributions $[6,7]$. The capstone design course provides a challenging open-ended project that is supported by an instructor and an industry sponsor, both providing feedback and advice. Tutorials in the capstone course are designed to address skill gaps for students as they work on their design project. They provide an opportunity for students to direct their own learning, to develop their skills, to contribute to their team, and to complete their design projects successfully. Students with lower skill levels may experience anxiety or stimulation as they attempt to complete their project, as shown in Figure 1. The teaching in the capstone design course is intended to reduce student anxiety and to support skill development. The teaching (in the form of online instructional and reference materials) is available when students need it even if the instructor is not. Students, who have already developed skills, can challenge in class activities ahead of schedule. Students may approach the flow region from 
the motivational perspective. They have the skills and they have been presented with the challenge. The need to address a broad range of entry skill levels is typical for capstone design student cohorts because students from all programs including co-op, and traditional streams, with differing specialties and experiences are taught jointly.

\subsection{Tutorial Structure and Content}

The new teaching format is designed to enhance student engagement by converting existing lecture materials into brief videos students watch prior to class. Table 1 compares the previous lecture and the current flipped format. Pre-class materials introduce a topic and link it to project requirements. The teaching objective is to connect with all students regardless of entry skill level and to develop the skills rapidly to a higher level using a shared experiential approach. Typically videos are limited to 5-6 minutes as they are "information dense". A one-hour lecture can often be compressed to fifteen minutes of video presentation. However, students need time to reflect in between [8] and two or three shorter videos are easier to review. A tutorial topic is further developed in class with an activity to apply the pre-class material. Student discussions within teams and in larger groups are built into in-class activities, as are opportunities for students to share their findings with the class and leverage learning.

There is a brief assignment, usually a report on the results of the activity that is due at the end of class. Students are given an opportunity to apply the teaching in class. Instructors are available to answer questions and to help if required. The in-class assignments are typically relevant to all design project requirements. Post tutorial learning elements extend the in class learning and link further skill and knowledge development to individual design project and final report requirements.

Post-class, individual students and design teams apply their learning to their design projects. For example, the topic "Team Formation and Team Management" includes short readings, a self-assessment and a video prior to class. In class, case studies describing poorly performing teams are discussed and evaluated, and outcomes presented to the class as a whole by groups of teams. Following the class, each design team prepares a charter outlining their team structure, their expectations of one another and their performance deviation management plan.

Tutorial content was developed based on existing course objectives that are correlated to the Canadian Engineering Accreditation Board Graduate Attributes Assessment (CEAB GAA). Tutorials provide a review and further development of key areas related to Chemical Engineering fundamental knowledge, and its application in the design process. In addition, an overall course plan was created and learning objectives were developed for individual tutorials. An integrated instruction strategy with the introductory design course was also developed.

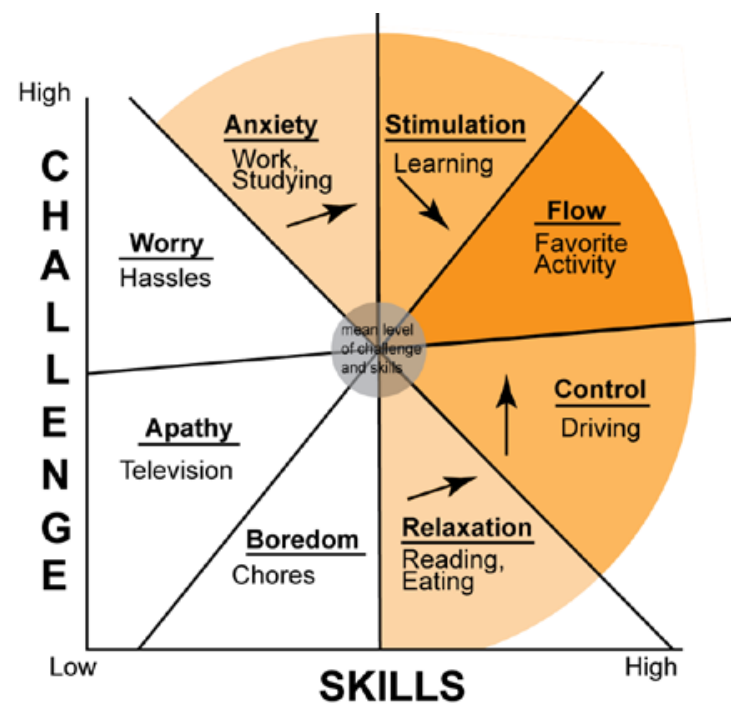

Stimulation and Control both directly correlate to learning

Fig. 1. Flow Diagram Adapted from Csikszentmihalyi (1990)

Table 1: Tutorial Structure

\begin{tabular}{|c|c|}
\hline Previous Format & Flipped Format \\
\hline No pre class work & Pre class work $(\sim 0.5 \mathrm{~h})$ \\
\hline Traditional Lecture (2h) & Active Learning $(1 \mathrm{~h})$ \\
\hline $\begin{array}{c}\text { Weekly Team Meeting }(0.5 \mathrm{~h}) \\
\text { Project Time }(1.5 \mathrm{~h}+2 \mathrm{~h})\end{array}$ & $\begin{array}{c}\text { Weekly Team Meeting }(0.5 \mathrm{~h}) \\
\text { Project Time }(2.5 \mathrm{~h}+3 \mathrm{~h})\end{array}$ \\
\hline
\end{tabular}

\section{EVALUATION METHODS}

Previously, student teams self-assessed, and were assessed by instructors based on their performance ahead of and during meetings that linked interim deadlines for producing a planning document for their course work, a mass and energy balance for their process, a final presentation of their findings, as well as a final report. The final report comprised $80 \%$ of the course mark and was summative in nature.

To provide ongoing feedback and opportunities for students to develop their skills, enhanced self-assessment and formative assessment tools were included as part of the course redesign. A CEAB based skills and attributes self-assessment tool was developed to determine how students viewed themselves prior to and following the course. Data collection was automated and students made use of the pre-course assessments to select teams. Formative assignments related to tutorial topics and final report requirements were also added. The project 
planning and the final reports continue to be summative assessments and comprise $80 \%$ of the course mark.

\subsection{Individual and Team Assessment}

To assess the scope and quality of the contributions of individuals to team performance, and team performance as a whole, two formative assignments are repeated during each of the four phases of the course: researching and developing a client proposal; engineering analysis and design; project analysis; and on completion.

Team evaluation forms were developed for students to rate themselves and team members individually based on the quality and quantity of their contributions to the work done at each phase. At a team meeting, students compare and discuss individual results then prepare and submit a rating table that includes both self and average team assessed ratings for individual students. All team members sign the submitted copy of the ratings table. The discussion of this evaluation is private to the team.

After considering individual behaviors, students are then asked to reflect on team, technical and project logistics performance and to rank their team according to criteria in a reflection tool based on group dynamics, adapted from Newell et al. [13]. Behaviors observed in design teams and correlated with capstone project grades are described. Student teams are asked to comment on the ongoing development of their team skills relative to this rubric and to submit an account of their observations and plans for improvement at each major project milestone.

\subsection{Individual Self-Assessment}

Just prior to the course, individual students self-assess their skills and abilities using the online CEAB GAA tool. Students are able to assemble a team and view their team composite skill and attribute data prior to finalizing their team selection. The goal is to assemble a balanced team. The self-selected teams are accountable for ensuring they have the skills required, for establishing an agreed upon team structure, team values, performance and work quality norms. Students repeat the individual CEAB skill self-assessment at the end of the course. The composite data is used for course effectiveness evaluation. Examples are provided in the Results section.

\subsection{Formative Assessment}

All milestone and portfolio assessments are formative. The students are marked on completion of the requirements. The marking scheme is based on completion and on-time criteria as outlined in Table 2.
Table 2: Formative Assignment Structure

\begin{tabular}{|l|l|}
\hline \multicolumn{1}{|c|}{ Milestone Assignments } & \multicolumn{1}{|c|}{ Portfolio Assignments } \\
\hline $\begin{array}{l}\text { Based on product delivery } \\
\text { Project based } \\
\text { Phase completion }\end{array}$ & $\begin{array}{l}\text { Based on developing } \\
\text { Tutorial based } \\
\text { Starting point for project }\end{array}$ \\
\hline $\begin{array}{l}\text { Marking: complete, on time, } \\
\text { received by sponsor }\end{array}$ & $\begin{array}{l}\text { Marking: complete, on time, } \\
\text { thoughtful, reflect activity }\end{array}$ \\
\hline
\end{tabular}

\subsection{Assignment Retention for CEAB Evaluation}

All assignment related materials and supporting documents are accessed online, and all assignments are submitted online by each team within a Moodle learning management system. The course is stored by cohort and all information can be retrieved electronically including examples of students' work. The use of online materials and student progress are both tracked and all the information is retained and accessible following the course. As course work is graded by team, the development of a team and their project can be reviewed along with the materials the team accessed, their in class participation, and project milestone progress including individual student contributions and time sheets. The ready availability of detailed data sets for individual teams, linked to grades and CEAB attributes is expected to facilitate the next CEAB review, scheduled for 2017.

\subsection{Data Gathering Methods}

Data were gathered during the course for the purpose of evaluating the effectiveness of instructional methods and student engagement. Student access of online material was tracked and collected. Individual student timesheets and contributions to their team project were tracked using weekly reports. All students were asked for course feedback on a regular basis. Effectiveness is being evaluated by comparing performance with previous cohorts, improvements in post course student selfassessment, student engagement and satisfaction surveys.

\subsection{Online Access Monitoring}

Individual access to online materials was recorded on e-class and reported by team. Students submitted one assignment per team. Time of assignment submission was automatically recorded. This particular feature was in place for the previous cohort.

Heat maps (Figure 2) were developed to visualize resource usage by teams. In this example, the frequently accessed items are the pre tutorial videos (bottom four rows), samples (top yellow band), materials for in-class activities and assignments (mid yellow band). Resource materials and alternate delivery modalities (previous 
lecture notes - top purple) were accessed less frequently if at all.

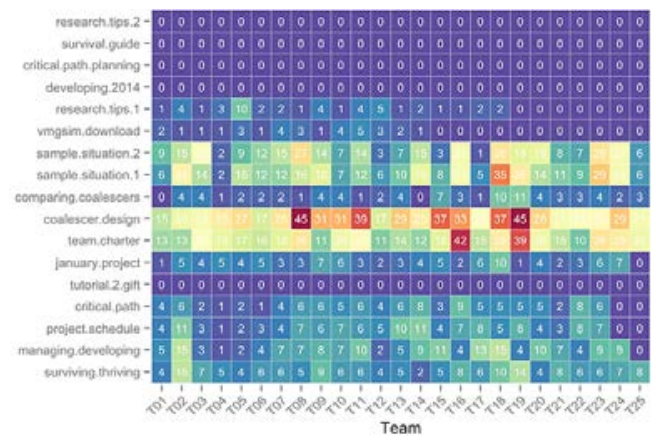

Fig. 2. Tutorial 2 Heat Map of Online Material Access

Frequency distributions were used to determine how often on-line materials were accessed and when in relation to the relevant tutorial. Certain materials were accessed on an ongoing basis as students were developing their own work and pre tutorial materials were typically accessed prior to class. Figure 3 provides the frequency and timing of student access to an example interim report. Access by each team, tracked by colour, is spread over a two-week period. By contrast, pre-class video access frequency charts show a dense cluster of points twenty four to thirty hours prior class.

\subsection{Instructor Observations}

The instructors and the teaching assistant (TA) were asked to make notes after tutorials regarding observations on student engagement, learning, quantity and quality of questions students asked, and changes from the previous cohort to the pilot cohort. Observations were made regarding when students submitted assignments relative to due dates, assignment completeness and quality.

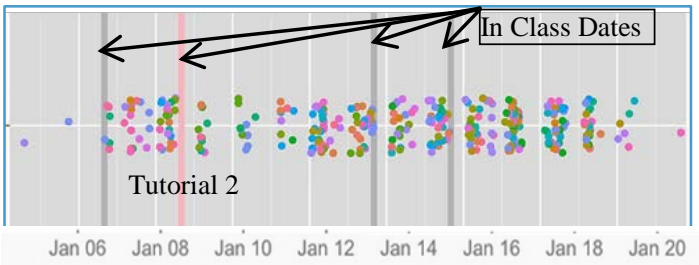

Fig. 3. Frequency and Timing of Student Access

\subsection{Student Feedback}

Student feedback on the course was collected in the form of surveys after the first month of the course, after a specific new tutorial and at the end of the course. The intermediate feedback surveys were based on students' perceptions of whether or not the course objectives were being met and whether the learning objectives for a specific tutorial were being met.

\section{RESULTS}

Results at the time of writing are preliminary and are based on observations during the term, resource access frequencies, preliminary comparative $\mathrm{CEAB}$ GAA results, and preliminary student feedback. A complete data analysis and course evaluation is in progress. We plan to use access data, student feedback and final report results to improve course organization and delivery. Initial findings of the student access of online resources is promising and methods to gather data on individual and team access, timing and frequency of access are providing a promising framework for automating data collection, the collection of student example work, and formative assessments in the capstone course.

\subsection{CEAB Self-Assessment of Skills}

The before and after comparison of student selfassessment of CEAB GAA data is in progress. At the time of writing $30 \%$ of the class (more than 40 students) has completed the post-course assessment. Figure 4 shows students' views of their pre and post course ability to design a process system. Figure 5 shows the progress the students' views of their ability to develop competence. The development of skills for lifelong learning is a critical aspect of an engineering education and a core goal for the CEAB GAA.

\subsection{Course Effectiveness Evaluation}

Observations and data indicate some teams watched the videos together, some individually and some skipped them altogether. All teams attended all class activities and handed in assignments. The course effectiveness is not being evaluated on whether or not students were able to check off all activities as complete but rather that students accessed materials necessary for their individual development and project completion. Ongoing evaluation will address the issue of ensuring that online materials address student learning modalities and enhance student skills required to develop and complete a team based capstone design project. One change being considered is to remove resources from the main block in Moodle to a separate Resource section. Highlighting key items was requested by students.

Instructor notes are invaluable in the improvement process. All instructors reported increased student engagement and interaction in class and in the weekly meetings. The depth of the questions students asked had increased as the level of engagement increased. 


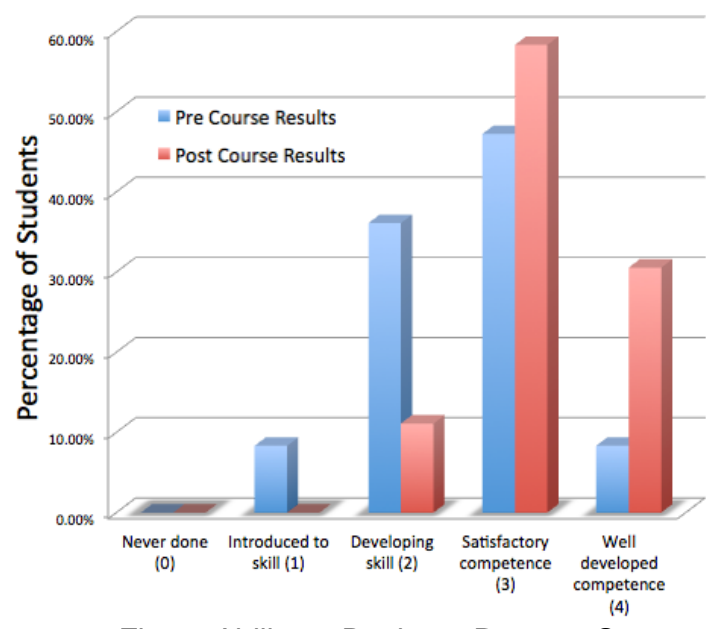

Fig. 4. Ability to Design a Process System

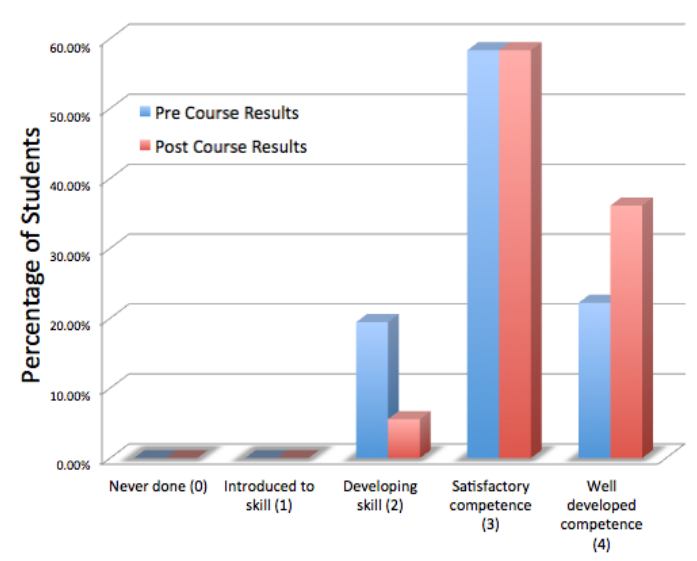

Fig 5. Ability to Develop Competence

\section{CONCLUSIONS}

The ability to improve course effectiveness based on student feedback and project quality is enhanced by understanding student use of resources and engagement.

Addressing the variation of incoming student skill levels by asynchronous online instruction techniques improves the overall experience for students and instructors in the course.

Automated tracking and consolidation of data facilitates preparation for $\mathrm{CEAB}$ and other reviews and undergraduate curriculum development more broadly.

\section{Acknowledgements}

The course redevelopment was funded by the University of Alberta's Provost Office. We would like to acknowledge the support given throughout the course by the following: Rishi Jaipaul and the CTL production staff, Enrico Indiogine, Suzanne Kresta and the 2015 graduates of Chemical Engineering Design Class.
[1] Alexander Astin, What Matters in College?: Four Critical Years Revisted. San Francisco, CA: Jossey-Bass, 1993, 512 pp. \{ISBN: 978-0787-90838-9\}

[2] Ann E. Austin, "Promoting evidence-based change in undergraduate science education," in the Forth Committee Meeting on Status, Contributions, and Future Directions of Discipline-Based Education Research, (Washington, D.C.; 1 March 2011), 25 pp., 2011.

[3] Mihaly Csikszentimihalyi, Flow: The Psychology of Optimal Experience. New York, NY: Harper \& Rowe, 1990, 303 pp. \{ISBN: 978-0060-16253-5\}

[4] Edward L. Cussler, "The future of the lecture,” American Institute of Chemical Engineers Journal, Advance Online Publication, 11 pp., 2015.

[5] Richard M. Felder, Rebecca Brent, and Michael J. Prince, “Engineering instructional development: Programs, best practices, and recommendations," Journal of Engineering Education, vol. 100, no. 1, pp. 89-122, 2011.

[6] Richard M. Felder and Michael J. Prince, "Inductive teaching and learning methods: Definitions, comparisons, and research bases," Journal Of Engineering Education, vol. 95, no. 2, pp. 123-128, 2006.

[7] Richard M. Felder and Michael J. Prince, "The case for inductive teaching," ASEE Prism, vol. 17, no. 2, pp. 55, 2007

[8] Donn R. Garrison and Norman D. Vaughan, Blended Learning in Higher Education: Framework in Principles, and Guidelines. San Francisco, CA: Jossey-Bass, 2008, 272 pp. \{ISBN: 978-0787-98770-1\}

[9] Donn R. Garrison and Norman D. Vaughan, "Institutional change and leadership associated with blended learning innovation: Two case studies," The Internet and Higher Education, vol. 18, pp. 24-28, 2013.

[10] Nancy Kober, Reaching Students: What Research Says About Effective Instruction in Undergraduate Science and Engineering. Washington, D.C.: National Academies Press, 2014, 256 pp. \{ISBN: 978-0309-30043-8\}

[11] Priscilla Laws, David R. Sokoloff, and Ronald Thornton, "Promoting active learning using the results of physics education research," UniServe Science News, vol. 14, pp. 14-10, 1999.

[12] Elena Martínez-Caro and Francisco Campuzano-Bolarín, "Factors affecting students' satisfaction in engineering disciplines: Traditional vs. blended approaches," European Journal of Engineering Education, vol. 35, no. 5, pp. 473-483, 2011.

[13] James A. Newell, Heidi L. Newell, and Kevin D. Dahm, "Rubric Development for Assessment of Undergraduate Research: Evaluating Multi Disciplinary Team Projects," Chemical Engineering Education, vol. 38, no. 1, pp. 68-73, 2004.

[14] Michael J. Prince, "Does active learning work? A review of the research,” Journal of Engineering Education, vol. 93, pp. 223-231, 2004.

[15] Susan R. Singer, Natalie R. Nielsen, and Heidi A. Schweingruber, Discipline-based Education Research: Understanding and Improving Learning in Undergraduate Science and Engineering. Washington, D.C.: National Academies Press, 2012, 282 pp. \{ISBN: 978-0309-25411-3\}

[16] Jeanne Nakamura and Mihaly Csikszentimihalyi, "The concept of flow," Handbook of Positive Psychology, pp. 89-105, 2002.

[17] Leonard Springer, Mary Elizabeth Stanne, and Samuel S. Donovon, "Effects of small-group learning on undergraduates in science, mathematics, engineering and technology: A meta-analysis," Review of Educational Research, vol. 69, no. 1, pp. 21-52, 1999.

[18] Norman D. Vaughan, “A blended community of inquiry approach: Linking student engagement and course redesign," The Internet and Higher Education, vol. 13, no. 1, pp. 60-65, 2010.

[19] Phillip C. Wankat, "Progress in reforming chemical engineering education," Annual Review of Chemical and Biomolecular Engineering, vol. 4, pp. 2343, 2013

[20] John Watson, "Promising Practices in Online Learning: Blended learning: The convergence of online and face-to-face education," North American Council for Online Learning, pp. 16, 2008. 